Opinion

\title{
Aquilaria malaccensis Lamk.: A Potential Bioresource for Shifting Cultivation Management, Livelihood Generation and Climate Change Mitigation in North East India
}

\author{
KRISHNA GIRI*, R S C JAYARAJ, GAURAV MISHRA and SATYAM BORDOLOI \\ Rain Forest Research Institute, Jorhat 785 001, Assam, India \\ (Indian Council of Forestry Research and Education, Dehradun, MoEF\&CC, Govt. of India)
}

The wood of Aquilaria malaccensis Lamk, is in high demand due to its medicinal and aromatic properties; which is used as medicine, incense and as fixative in perfumes in Asia and the Middle East. The higher demand of wood has caused over extraction of $A$. malaccensis from the wild habitats in North East (NE) India. Thus, the species has been declared as critically endangered and included in The International Union for Conservation of Nature and Natural Resources (IUCN) red data list. The unsustainable extraction of A. malaccensis from its natural forest and slash and burn agriculture practice in hilly terrains of North Eastern Region (NER) have led to the loss of rich biodiversity, soil erosion and land degradation. Conservation of $A$. malaccensis in its natural habitats and management of shifting cultivation are among the priority issues in NER. Therefore, introduction of the endangered tree species, $A$. malaccensis in degraded fallow jhum land and transformation of shifting cultivation through integrated high value agroforestry practices can help in the conservation of the above species. This integrated initiative may also provide better livelihood opportunities to tribal communities engaged in shifting cultivation practice.

Aquilaria malaccensis Lamk., belonging to the family Thymeleaceae is commonly known as agar tree has natural distribution in Bangladesh, Bhutan, India, Indonesia, Iran, Malaysia, Myanmar, Philippines, Singapore and Thailand (IUCN, 2013). In India, North Eastern region and West Bengal are the natural habitats of this tree species (Barden et al., 2000; Singh et al., 2015). A. malaccensis is also known as eaglewood and valued for its medicinal and aromatic properties. The market price of agar oil is equivalent to the gold and is hence known as black gold. Beniwal (1987) stated that the resin or agarwood formation in A. malaccensis is believed to be result of the physiological changes in the tree due to fungal infection. This hypothesis is still being investigated for elucidation of actual mechanism of resin formation as a result of biological interaction between plant and microbes. Due to unique charismatic medicinal and aromatic properties and huge monetary value, it's over exploitation and indiscriminate extraction from the wild has caused drastic population depletion from its natural distribution ranges in NE. The species has been considered critically endangered in India (IUCN, 2009) and listed in Appendix II (potentially threatened species) of the Convention on International Trade in Endangered Species of Wild Fauna and Flora (CITES, 2010), also included in IUCN red data list in the year 2011, while it is near to the extinction from the natural forests (Saikia and Khan, 2012) and almost extinct in wild from Assam (Saikia and Khan, 2013).

Shifting cultivation, a major agricultural land use practice in hill states of NE India and hill districts of Assam is challenging environmental issue in this region. Due to undulating and rigorous geographical condition and socio-economic impediments, tribal communities are bound to practice jhum cultivation in natural forest areas (Ramakrishnan, 1992). The extensive jhuming has caused the loss of biodiversity, soil erosion and land degradation in the region, while burning of large scale plant biomass is a major source of carbon dioxide emission. Though the jhum cultivation with long fallow period of 15-25 years is seems to be a sustainable practice. However, increasing population and food grain demand and decreasing traditional jhum

*Author for Correspondence: E-mail: krishna.goswami87@gmail.com 
fallow length of 3-5 years has made this system unproductive and an unsustainable farming practice. Due to over extraction of $A$. malaccensis from the wild, it is now mostly confined into homestead gardens and private plantations. The naturally infected trees fetch a very high price and make it a potential bioresource for livelihood of people in NE India. Besides, several studies are being undertaken on artificial agarwood induction in $A$. malaccensis using physical, chemical and biological methods in India and other countries of its distribution. The attempts of artificial agarwood induction have further increased the value of this tree. In view of the facts described above on two priority issues of NE India, it is opined that introduction of $A$. malaccensis in degraded jhum lands can be a move towards the conservation of this tree species in its natural habitats and minimization or sustainable management of shifting cultivation. The opinion is focused on the conservation of large population of this important tree species in fallow jhum land which can be converted in to an agroforestry system. Cultivation of A. malaccensis in fallow jhum lands will conserve the declining population on one hand and transform rampant jhuming in to integrated agroforestry on the other. Through this integrated approach, cultivation of local crop verities will be continue as business as usual but under agroforestry rather than slash and burn system.

\section{Shifting cultivation management}

Introduction of agar trees in degraded jhum fields will enhance the green cover and gradually transform shifting to the settled cultivation. Integrated tree-crop cultivation through crop diversification viz. nitrogen fixing indigenous leguminous pulses i.e. rice bean (Vigna umbellata), french bean (Phaseolus vulgaris), soybean (Glycine max), velvet bean (Mucuna pruriens) and pigeon pea (Cajanus cajan) during fallow period followed by crop rotation with vegetables, maize, paddy and millets under mature stands of $A$. malaccensis will minimise the slash and burn operations and loss of natural biodiversity. The legume crops have been found suitable for soil fertility and productivity enhancement through biological nitrogen fixation (BNF) and organic matter addition by residual biomass decomposition. Intensification of annual leguminous crops in fallow jhum land is already being practiced in traditional manner by the jhumia farmers in Nagaland. These crops have dense foliage and grown for soil protection and nitrogen fixation. The integrated tree-crop model will also be helpful for enhanced rhizospheric microbial activities and soil health improvement, as active microbial population in the rhizosphere zone is reported to be 10-100 folds higher than the bulk soil (Weller and Thomashow, 1994).

\section{Livelihood options}

Presently the value of agarwood is very much high in the market and the price of raw material is decided upon the quality of agarwood. Therefore, mature Aquilaria trees in jhum fields can be artificially inoculated with potential microbial strains for agarwood formation through traditional and scientific interventions. Beside, in certain agro climatic zones, natural infection in agar trees may also take place. Formation of resin or agarwood provides huge monetary benefit to the farmers, therefore large scale agarwood plantation in jhum fields along with cultivation of local crop verities under the plantations will also pave the ways of advance research in artificial agarwood induction and development of sustainable agroforestry models. The actual mechanism of agarwood formation by the interaction between tree and microbes is still an ambiguity. Hence, omics studies of plant microbe interaction can unravel the agarwood formation mechanisms, for which large population of agar trees in different agro climatic zones will be required. A Cyclic process of harvesting of infected agar trees followed by plantations of new seedlings along with regular crop cultivation under the plantation will prove itself as an economically viable high value agroforestry practice and control the slash \& burn agriculture. The Cyclic slash and burn agriculture can be gradually replaced by the cyclic Aquilaria based agroforestry practices. This practice can also be helpful to reintroduce Aquilaria in its natural habitat range to compensate the loss of natural population of this precious species (Saikia and Khan, 2012).

\section{Climate change mitigation}

Burning of huge plant biomass during slash and burn operations for crop cultivation is a direct source of carbon dioxide emission in the environment. Considering the issues of emission reduction and climate change mitigation, management of shifting cultivation through agar based agroforestry practices 
will contribute to climate change mitigation on one hand and conservation of biodiversity, soil, water and land resources on the other. This opinion of authors is in tune of National Mission for Sustaining Himalayan Ecosystem under the National Action Plan on Climate Change, where conservation of biodiversity, traditional knowledge, societies and their livelihood are among the priority area of the mission. Harvesting of agarwood from its natural habitats has been banned in India. While, harvesting from plantations is permissible provided the plantations are registered with the Forest Department of the concerned states. However, there is no regulation on community lands

\section{References}

Barden A, Awang A, Mulliken T and Song M (2000) Heart of the matter: agarwood use and trade and CITES implementation for A. malaccensis, TRAFFIC International, Cambridge, UK

Beniwal B S (1987) Silvicultural characterstics of Aquilaria agallocha Roxb. Arunachal forest news 531-33

Ibrahim M Dutta R K and Jayaraj R S C (2018) Know your trees-Aquilaria malaccensis. ENVIS Newsletter, Forest Genetic Resources and Tree Improvement, Van Vigyan, Institute of Forest Genetics and Tree Breeding (Indian Council of Forestry Research and Education) 5 2-5

IUCN (2009) Asian Regional Workshop (Conservation \& Sustainable Management of Trees, VietNam), 1998. Aquilaria malaccensis. In: IUCN 2009. IUCN Red List of Threatened Species

IUCN (2013) IUCN Red List of threatened species, version 2013.2. http://www.iucnredlist.org/details/32056/0.

Ramakrishnan P S (1992) Shifting Agriculture and Sustainable Development: An Interdisciplinary Study from North- where the species exists (Ibrahim et al., 2018). Therefore, large scale plantation of this potential bioresource in community owned abandoned jhum fields will be of immense importance for species conservation, jhum transformation in to agroforestry system and improved livelihood opportunities of rural communities in NE India. Replacement of jhum cultivation by agar based agroforestry system will minimise the slash and burn operations and green house gas emission. Adoption of this integrated farming practice has tremendous climate change mitigation potential in NE India.

Eastern India. UNESCO-MAB Series, Paris, Parthenon Publ., Carnforth, Lancs, UK, 424 pp. (Republished by Oxford University Press, New Delhi

Saikia P and Khan M L (2012) Seedling survival and growth of Aquilaria malaccensis in different microclimatic conditions of northeast India $J$ For Res 23 569-574

Saikia P and Khan M L (2013) Population structure and regeneration status of Aquilaria malaccensis Lam. in home gardens of Upper Assam, Northeast India Trop Ecol 54 113

Singh P, Nag A, Parmar R, Ghosh S, Bhau B M and Sharma R K (2015) Genetic diversity and population structure of endangered Aquilaria malaccensis revealed potential for future conservation J Genet 94 697-704

Weller D M and Thomashow L S (1994) Current Challenges in Introducing Beneficial Microorganism into the Rhizosphere. In: Molecular Ecology of Rhizosphere Microorganisms: Biotechnology and Release of GMOs pp. 1-18. 